дение», Волгоградский государственный аграрный университет. Россия.

400002, г. Волгоград, просп. Университетский, 26. Тел.: (8442) 41-12-20.

Солодовников Анатолий Петрович, $\partial-p$ c.- $x$. наук, проф. кафедры «Земледелие, мелиорация и агро- химия», Саратовский государственный аграрный университет имени Н.И. Вавилова. Россия.

410012, г. Саратов, Театральная пл., 1.

Тел.: (8452) 26-16-28.

Ключевые слова: подсолнечник; прямой посев; гибриды; гербициды; удобрения.

\title{
NONCONVENTIONAL INTERCROP WAYS OF RECEIVING ALFALFA SEEDS
}

Pleskachev Jury Nikolaevich, Doctor of Agricultural Sciences, Professor, Head of the chair "Agriculture and Agrochemistry”, Volgograd State Agrarian University. Russia.

Semina Natalia Ivanovna, Candidate of Agricultural Sciences, Assistant of the chair "Agriculture and Agrochemistry", Volgograd State Agrarian University. Russia.

Dolgov Evgeniy Yurievich, Competitor of the chair "Agriculture and Agrochemistry", Volgograd State Agrarian University. Russia.

Skorokhodov Yevgeniy Antonovich, Candidate of Agricultural Sciences, Assistant of the chair "Technology of Production, Processing of Livestock Products and Commodity Science", Volgograd State Agrarian University. Russia.
Solodovnikov Anatoly Petrovich, Doctor of Agricultural Sciences, Professor of the chair "Agriculture, Melioration and Agrochemistry", Saratov State Agrarian University named after N.I. Vavilov. Russia.

Keywords: sunflower; direct seeding; hybrids; herbicides; fertilizers.

Hybrids of sunflower with a system of protection against weeds and diseases and mineral fertilizers are considered when cultivating in the zone of chernozems common. It was found out that the most effective was the cultivation of the Mugly hybrid with the EuroLife herbicide and the Picktor fungicide, as well as the introduction of ZHKU into the phase of 2-4 leaves at the rate of $120 \mathrm{l} / \mathrm{ha}$.

удк 653.63:631.62:661.162.6 [470.44]

\section{ВЛИЯНИЕ ГУМИНОВЫХ ПРЕПАРАТОВ НА ПРОДУКТИВНОСТЬ ОГУРЦА НА ОРОШАЕМЫХ КАШТАНОВЫХ ПОЧВАХ САРАТОВСКОГО ЗАВОЛЖЬЯ}

\author{
ПРОНЬкО Нина Анатольевна, Саратовский государственный аграрный университет \\ имени Н.И. Вавилова
}
СТЕПАНЧЕНКО Денис Александрович, Саратовский государственный аграрный университет имени Н.И. Вавилова

\section{ПРОНЬКО Виктор Васильевич, НПО «Сила жизни»}

В полевъх опытах на орошаемъх террасовых темно-каштановъх почвах Саратовского Заволжъя изучено влияне препаратов на основе гуминовых кислот, производимых НПО «Сила жизни», на урожайность и качество огуриа гибрида Меринго. Установлено, что однократное опрыскивание раствором гумата калия-натрия с микроэлементами повысило урожайность товарнъх плодов в среднем за три года на 24 \% по сравнению с контролем. При использовании реасила гидро микс прирост урожая составил 36 \%. Двукратное применение на фоне этих обработок реасила форте азот гумик или реасила форте кальиий- магний-бор амино позволило повъсить урожайность плодов на 51 $52 \%$. Обработки растений огуриа растворами препаратов на основе гуминовъх кислот способствовали увеличению содержания в плодах соединений азота, калия, суммы сахаров и витамина С. Нитратов в урожса всех вариантов содержсалосъ примерно в 5 раз ниже предельно допустимого уровня.

Введение. В современном земледелии широко практикуется использование микроэлементных удобрений, препаратов на основе гуминовых кислот и регуляторов роста растений [7]. В Российской Федерации их производством занимаются более 60 организаций. Выпускаемые препараты существенно отличаются между собой по химическому составу, что требует проведения научных испытаний для определения эффективных условий их использования (способы применения, дозы, сроки, степень отзывчивости растений и т.п.).

Одним из самых крупных производителей микроэлементных удобрений и препаратов на основе гуминовых кислот является НПО «Сила жизни». Его продукция широко используется при возделывании зерновых, 
кормовых и технических культур не только в Поволжье, но и в других регионах Российской Федерации [2].

Результаты многочисленных исследований и производственные испытания показали, что среди сельскохозяйственных культур наибольшей отзывчивостью на гуминовые и микроэлементные препараты отличаются овощные растения. В научной литературе имеются сведения о высокой эффективности их применения на моркови [3], столовой свекле [4], томате [6], При возделывании огурца ранее подобные препараты не испытывались.

Цель наших исследований - изучить отзывчивость растений огурца, районированного гибрида Меринго, на микроэлементные и гуминовые удобрения в условиях орошения на темно-каштановых почвах Саратовского Заволжья.

Методика исследований. Объекты исследований - огурец (гибрид $\mathrm{F}_{1}$ Меринго) и препараты на основе гуминовых кислот, производимые НПО «Сила жизни» (г. Саратов). В их состав входит следующее (в весовых процентах). Гумат калия натрия с микроэлементами: $\mathrm{N}_{\text {общ }}-3,5 \%, \mathrm{P}_{2} \mathrm{O}_{5}-0,5 \%, \mathrm{~K}_{2} \mathrm{O}-2,5 \%$, $\mathrm{Mg} \mathrm{O}-0,1 \%, \mathrm{~B}-0,1 \%$, Co - 0,01 \%, Cu 0,05 \%, Fe - 0,12 \%, Mn - 0,1 \%, Mo - 0,025\%, Zn - 0,12 \%, соли гуминовых кислот - 7,0 \%, гидроксикарбоновые кислоты - 0,6 \%, аминокислоты - 2,4 \%. Реасил микро гидро микс: $\mathrm{N}_{\text {обш }}-12,0 \%, \mathrm{Mg} \mathrm{O}-4,0 \%, \mathrm{~B}-2,0 \%$, Co $0,1 \%, \mathrm{Cu}-0,8 \%, \mathrm{Fe}-5,0 \%, \mathrm{Mn}-2,5 \%$, Мо - 0,25 \%, Zn - 3,0 \%, гидроксикарбоновые кислоты - 18,0 \%, аминокислоты - 8,0 \%. Реасил форте магний амино: $\mathrm{N}_{\text {общ }}-18,0 \%$, $\mathrm{Mg} \mathrm{O} \mathrm{-} \mathrm{14,0} \mathrm{\% ,} \mathrm{гидроксикарбоновые} \mathrm{кислоты} \mathrm{-}$ 14,0 \%, аминокислоты - 4,0 \%. Реасил микро амино марганец: $\mathrm{N}_{\text {общ }}-10,0 \%, \mathrm{Mn}-10,0 \%$, гидроксикарбоновые кислоты - 18,0 \%, аминокислоты - 8,0 \%. Реасил микро амино медь: $\mathrm{N}_{\text {общ }}-10,0 \%, \mathrm{Cu}-10,0 \%$, гидроксикарбоновые кислоты - 20,0 \%, аминокислоты - 8,0 \%. Реасил форте азот гумик: $\mathrm{N}_{\text {общ }}-20,0 \%$, соли гуминовых кислот - 6,0 \%, гидроксикарбоновые кислоты - 2,0 \%, аминокислоты - 6,0 \%. Реасил форте кальций-магний-бор амино: $\mathrm{N}_{\text {общ }}-18,0 \%, \mathrm{CaO}-12,0 \%, \mathrm{MgO}-4,0 \%$, В - 4,0\%, гидроксикарбоновые кислоты $18,0 \%$, аминокислоты - 4,0 \%.

Полевые опыты по изучению эффективности препаратов проводили в 2014-2016 гг. в КФХ «Семья Жайлауловых» (Энгельсский p-н Саратовской обл.) в условиях орошения. Почва опытного участка темно-каштановая на террасе левого берега Волги, среднегумусная среднесуглинистая несолонцеватая, имеет низкие запасы доступных для растений соединений азота и фосфора, а обменного калия высокое. Полив осуществляли установкой мелкодисперстного дождевания Райн Стар E-41. Поливная норма по годам исследований колебалась от 500 до $600 \mathrm{M}^{3} /$ га. Число поливов за вегетацию изменялось от 4 (2014 г.) до 5 (2015-2016 гг.).

Размер учетной площади делянки составлял $35 \mathrm{~m}^{2}$, повторность вариантов четырехкратная. Ежегодно закладывали по два опыта. В опыте 1 в качестве фона использовали гумат калия-натрия с микроэлементами, а в опыте 2 - реасил микро гидро микс. Водными растворами этих препаратов (из расчета по 1,0 л/га) проводили опрыскивание растений огурца при появлении 3 настоящих листьев. Затем с интервалами в среднем 20 дней дважды опрыскивали посевы препаратами, указанными в табл. 1. Норма расхода реасила форте азот гумик составляла 3,0 л/га, а всех других препаратов - по 1,0 л/га на каждую обработку. Опрыскивание посевов и уборку урожая осуществляли вручную.

Постановку полевых опытов и дисперсионный анализ полученных результатов осуществляли по Б.А. Доспехову [1]. Анализ химического состава урожая производили по общепринятым методикам [5]. Азот, фосфор, калий определяли после мокрого озоления навески - по Гинзбург, нитратный азот ионометрически в растворе алюмокалиевых квасцов, сахар в плодах - по Бертрану, витамин С (аскорбиновая кислота) - по Мурри после экстрагирования смесью соляной и метафосфорной кислот.

Результаты исследований. За время проведения полевых опытов погодные условия вегетационного периода складывались неодинаково. Это отразилось на количестве сборов и величине урожайности товарной продукции. В 2014 г. было 6 сборов плодов огурца, в 2015 г. -7 и в 2016 г. -8.

Наиболее благоприятным для роста и развития растений огурца оказался вегетационный период 2015 г. Самые плохие погодные условия сложились в 2016 г. В связи с этим в 2016 г. урожайность огурца на контрольном варианте опыта 1 оказалась в 2,5 раза ниже, чем 2015 г., а на опыте 2 - в 1,5 раза (табл. 1 ). 


\section{Урожайность огурца гибрида Меринго, т/га}

\begin{tabular}{|c|c|c|c|c|c|c|c|}
\hline \multirow{3}{*}{ Вариант опыта } & \multirow{3}{*}{2014 г. } & \multirow{3}{*}{2015 г. } & \multirow{3}{*}{2016 г. } & \multirow{3}{*}{$\begin{array}{c}\text { Сред- } \\
\text { нее }\end{array}$} & \multicolumn{3}{|c|}{ Прибавка } \\
\hline & & & & & \multicolumn{2}{|c|}{ к контролю } & \multirow{2}{*}{$\begin{array}{c}\text { к фону } \\
\text { т/га }\end{array}$} \\
\hline & & & & & $\mathrm{T} /$ га & $\%$ & \\
\hline \multicolumn{8}{|c|}{ Опыт 1} \\
\hline 1. Контроль & 14,18 & 28,44 & 13,69 & 18,77 & - & 100 & - \\
\hline $\begin{array}{l}\text { 2. Гумат калия-натрия с микроэле- } \\
\text { ментами (фон) }\end{array}$ & 23,00 & 32,06 & 14,88 & 23,31 & 4,54 & 124 & - \\
\hline 3. Фон + реасил Mn & 28,43 & 36,85 & 16,19 & 27,16 & 8,39 & 145 & 3,85 \\
\hline 4. Фон + реасил $\mathrm{Mg}$ & 27,72 & 33,99 & 17,55 & 26,42 & 7,65 & 141 & 3,11 \\
\hline 5. Фон + реасил $\mathrm{Cu}$ & 27,15 & 32,58 & 18,28 & 26,00 & 7,23 & 139 & 2,69 \\
\hline 6. Фон + реасил $\mathrm{N}$ & 26,98 & 38,66 & 19,51 & 28,38 & 9,61 & 151 & 5,07 \\
\hline 7. Фон + реасил Сa/Mg/B & - & 36,78 & 20,17 & 28,48 & 9,71 & 152 & 5,17 \\
\hline $\mathrm{HCP}_{0,5}, \mathrm{~T}$ & 2,87 & 3,12 & 2,22 & & & & \\
\hline \multicolumn{8}{|c|}{ Опыт 2} \\
\hline 1. Контроль & 19,43 & 25,03 & 17,01 & 20,49 & - & 100 & - \\
\hline 2. Реасил гидро микс & 30,47 & 33,08 & 19,94 & 27,83 & 7,34 & 136 & - \\
\hline 3. Фон + реасил Mn & 28,41 & 37,32 & 22,77 & 29,50 & 9,01 & 144 & 1,67 \\
\hline 4. Фон + реасил Mg & 31,03 & 34,92 & 22,56 & 29,51 & 9,02 & 144 & 1,68 \\
\hline 5. Фон + реасил $\mathrm{Cu}$ & 28,06 & 32,98 & 23,64 & 28,23 & 7,74 & 138 & 0,40 \\
\hline 6. Фон + реасил $\mathrm{N}$ & 28,72 & 36,97 & 24,41 & 31,03 & 10,51 & 151 & 3,17 \\
\hline 7. Фон + реасил Сa/Mg/B & - & 37,96 & 24,28 & 31,12 & 10,63 & 152 & 3,29 \\
\hline $\mathrm{HCP}_{0,5}, \mathrm{~T}$ & 2,94 & 3,49 & 2,31 & & & & \\
\hline
\end{tabular}

Однократная обработка растений в фазу трех настоящих листьев раствором гумата калия-натрия с микроэлементами дозой 1,0 л/га в среднем за три года повысила урожайность плодов в опыте 1 на $24 \%$. Особенно эффективной она оказалась в условиях 2014 г.

Добавление к гуминовому препарату микроэлементных удобрений оказало статистически достоверное влияние на урожайность растений огурца. Однако действие микроэлементов в опыте 1 было неоднозначным. Из полученных нами трехлетних данных следует, что наиболее эффективно проявил себя реасил форте кальций-магний-бор амино (вариант 7). Двукратная обработка посевов позволила дополнительно получить 5,17 т/га плодов в среднем за три года. Применение реасила микро амино марганца дополнительно повысило урожайность огурца на 3,85 т/га. Препарат реасил микро амино медь дал прибавку урожая только 2,69 т/га.

Двукратная подкормка растений огурца азотсодержащим удобрением реасил форте азот гумик на фоне гумата калия натрия с микроэлементами (вариант 6) дала практически такие же результаты, как и тройная смесь микроэлементов на варианте 6.

В опыте 2 однократная обработка растений огурца микроэлементным препаратом реасил микро гидро микс (вариант 2) оказалась более эффективной, чем использование гумата калия натрия с микроэлементами в опыте 1. Проведение двукратных опрыскиваний растворами микроэлементов марганца (вариант 3), магния (вариант 4) и меди (вариант 5) на фоне реасила микро гидро микса хотя и дало положительные результаты, но прибавки урожая оказались в пределах наименьшей существенной разности. Только трехкомпонентная смесь кальция магния и бора (вариант 7) обеспечила значительный прирост урожайности. Такие же результаты в опыте 2 были получены и после проведе- 
ния азотных подкормок (вариант 6). Причины разной отзывчивости растений огурца Меринго на одни и те же микроэлементы в опытах, поставленных в одинаковых условиях, становятся понятными, если сравнить содержание отдельных микроэлементов в гумате калия-натрия с микроэлементами и в реасиле микс, которое приведено выше: в последнем их количество в несколько раз выше. Поэтому на основании полученных данных можно утверждать, что в опыте 2 добавление к насыщенному микроэлементами фону (вариант 2) марганца (вариант 3), магния (вариант 4) и меди (вариант 5) уже не имело практического значения. Усиление же обеспеченности микроэлементами гумата калия-натрия, в составе которого доминируют соли гуминовых кислот, аминокислоты и органические кислоты (опыт 1, вариант 2), дало положительные результаты.

В среднем за три года в экспериментальных условиях самые высокие сборы плодов огурца гибрида Меринго (31,03-31,12 т/га) обеспечили варианты, где на фоне реасила гидро микса проводили две азотные подкор- мки (по 3,0 л/га каждая) или двукратную обработку (по 1,0 л/га каждая) раствором реасила форте кальций-магний-бор амино. Анализ структуры биологического урожая показал, что повышение продуктивности на изучаемых вариантах происходило за счет увеличения средней массы плодов и их количества на единице площади.

Микроэлементные удобрения и препараты на основе гуминовых кислот оказали заметное влияние на химический состав плодов огурца гибрида Меринго (табл. 2). Так, азота и калия на всех изучаемых вариантах в плодах содержалось примерно на 10 \% больше, чем на контроле. Фосфора было больше в среднем на 5 \%. Это говорит о том, что все изучаемые нами микроэлементные препараты и препараты на основе гуминовых кислот способствовали лучшему развитию растений огурца и более активному потреблению ими питательных веществ из почвы. В плодах огурца, полученных с удобренных делянок, больше накапливалось сахаров и витамина С, что соответственно улучшило их качество. Количество нитратов во все годы исследований было в несколько раз

Таблица 2

Химический состав и качество плодов огурца гибрида Меринго (среднее за 2014-2016 гг.)

\begin{tabular}{|c|c|c|c|c|c|c|}
\hline \multirow{2}{*}{ Вариант опыта } & \multicolumn{3}{|c|}{ \% на абс. сухое вещество } & \multirow{2}{*}{$\begin{array}{c}\mathrm{NO}_{3}, \mathrm{Mг} / \\
\text { кг сырой } \\
\text { массы }\end{array}$} & \multirow{2}{*}{$\begin{array}{l}\text { Сумма са- } \\
\text { харов, \% }\end{array}$} & \multirow{2}{*}{$\begin{array}{c}\text { Витамин C, } \\
\text { мг/\% }\end{array}$} \\
\hline & $\mathrm{N}$ & $\mathrm{P}_{2} \mathrm{O}_{5}$ & $\mathrm{~K}_{2} \mathrm{O}$ & & & \\
\hline \multicolumn{7}{|c|}{ Опыт 1} \\
\hline 1. Контроль & 2,94 & 1,06 & 5,48 & 31,0 & 6,1 & 12,9 \\
\hline $\begin{array}{l}\text { 2. Гумат калий-натрий с микро- } \\
\text { элементами (фон) }\end{array}$ & 2,99 & 1,07 & 5,62 & 30,7 & 6,9 & 13,4 \\
\hline 3. Фон + реасил Mn & 3,02 & 1,12 & 5,58 & 32,7 & 6,9 & 13,4 \\
\hline 4. Фон + реасил $\mathrm{Mg}$ & 3,06 & 1,12 & 5,56 & 31,0 & 7,0 & 14,4 \\
\hline 5. Фон + реасил $\mathrm{Cu}$ & 3,06 & 1,11 & 5,58 & 29,3 & 7,0 & 13,5 \\
\hline 6. Фон + реасил $\mathrm{N}$ & 3,08 & 1,13 & 5,60 & 31,7 & 7,2 & 13,8 \\
\hline 7. Фон + реасил Сa/Mg/B & 3,01 & 1,12 & 5,61 & 28,4 & 7,3 & 13,6 \\
\hline \multicolumn{7}{|c|}{ Опыт 2} \\
\hline 1. Контроль & 3,10 & 1,03 & 5,35 & 30,3 & 6,2 & 13,4 \\
\hline 2. Реасил гидро микс & 3,20 & 1,03 & 5,36 & 31,0 & 6,5 & 14,2 \\
\hline 3. Фон + реасил Mn & 3,16 & 1,05 & 5,38 & 31,0 & 6,7 & 14,3 \\
\hline 4. Фон + реасил $\mathrm{Mg}$ & 3,17 & 1,06 & 5,42 & 30,7 & 6,8 & 14,4 \\
\hline 5. Фон + реасил $\mathrm{Cu}$ & 3,18 & 1,07 & 5,41 & 30,0 & 6,7 & 14,4 \\
\hline 6. Фон + реасил N & 3,21 & 1,08 & 5,44 & 31,0 & 6,7 & 14,5 \\
\hline 7. Фон + реасил Сa/Mg/B & 3,20 & 1,07 & 5,43 & 30,3 & 6,9 & 14,5 \\
\hline
\end{tabular}

Примечание: ПДК для нитратов в плодах огурца - 150 мг/кг сырой массы. 
ниже предельно допустимых норм и по всем вариантам опыта оно было одинаковым (30,032,7 мг/кг сырой массы).

Заключение. На орошаемых темно-каштановых террасовых почвах Саратовского Заволжья установлена высокая эффективность микроэлементных удобрений и препаратов на основе гуминовых кислот. В среднем за три года однократное опрыскивание растений огурца Меринго в фазу трех листьев препаратом реасил микро гидро микс в дозе 1,0 л/га увеличило сбор товарных плодов на $36 \%$. Аналогичная обработка гуматом калия-натрия с микроэлементами $(1,0$ л/га) повысила урожайность огурца на $24 \%$.

Самые высокие урожаи в условиях наших экспериментов (31,03-31,12 т/га, или $52 \%$ к контролю) обеспечивали варианты, где на фоне реасила микро гидро микс вносили двукратно азотную подкормку (по 3,0 л/га каждая реасилом форте азот гумик) или же дважды обрабатывали реасилом форте кальций-магнийбор амино (по 1,0 л/га) в каждую обработку.

Все изучаемые препараты производства НПО «Сила жизни» способствовали повышенному накоплению в плодах огурца азота, фосфора, калия, увеличивали содержание в них сахаров и витамина С. Нитратов в урожае во все годы исследований содержалось намного ниже предельно допустимых концентраций.

\section{СПИСОК ЛИТЕРАТУРЫ}

1. Доспехов Б.А. Методика полевого опыта. 5-е изд., перераб. и доп. - М., 1985. - 416 с.

2. Корсаков К.В., Пронько В.В. Повышение окупаемости удобрений при использовании пре- паратов на основе гуминовых кислот // Плодородие. - 2013. - № 2. - С. 18-20.

3. Корсаков К.В., Пронько В.В. Влияние гуминовых кислот на продуктивность моркови в Саратовском Заволжье при орошении // Вавиловские чтения - 2014: материалы Междунар. науч. конф. - Саратов, 2014. - С. 191-193.

4. Корсаков К.В., Пронько В.В. Влияние гуминовых препаратов на урожайность свеклы в Саратовском Заволжье: // Вавиловские чтения - 2014: материалы Междунар. науч. конф. Саратов, 2014. - С. 193-195.

5. Практикум по агрохимии / под ред. В.Г. Минеева. - 2-е изд., перераб. и доп. - М.: Изд-во Моск. ун-та, 2001. - 689 с.

6. Пронько Н.А., Пронько В.В., Степанчен$\kappa о$ Д.А. Влияние гуминовых препаратов на продуктивность томата на орошаемых каштановых почвах Саратовского Заволжья // Аграрный научный журнал. - 2017. - № 9. - С. 24-27.

7. Шеуджен А.Х., Онищенко Л.М., Пронько В.В. Удобрения, почвенные грунты и регуляторы роста растений. - Майкоп: Адыгея, 2005. - 404 с.

Пронько Нина Анатольевна, $\partial-p$ c.- $x$. наук, проф кафедры «Инженерные изыскания, природообустройство и водопользование». Россия.

Степанченко Денис Александрович, аспирант кафедры «Инженерные изыскания, природообустройство и водопользование». Россия.

410012, г. Саратов, Театральная пл., 1.

Тел.: (8452) 23-27-83.

Пронько Виктор Васильевич, $\partial-p$ c.-x. наук, проф., зав. отделом науки и развития, НПО «Сила жизни». Россия.

410005, г. Саратов, ул. Большая Садовая, 239.

Тел.: (8452) 44-40-40.

Ключевые слова: препараты на основе гуминовых кислот; огурец; орошение; темно-каштановые почвы.

\section{EFFECT OF HUMIC ACIDS PRODUCTS ON CUCUMBER PRODUCTIVITY ON IRRIGATED CHESTNUT SOILS OF THE SARATOV TRANSVOLGA REGION}

Pronko Nina Anatolyevna, Doctor of Agricultural Sciences, Professor of the chair "Engineering Surveying, Environmental Engineering and Water Management", Saratov State Agrarian University named after N.I. Vavilov. Russia.

Stepanchenko Denis Alexandrovich, Post-graduate Student of the chair "Engineering Surveying, Environmental Engineering and Water Management”, Saratov State Agrarian University named after N.I. Vavilov. Russia.

Pronko Viktor Vasilyevich, Doctor of Agricultural Sciences, Professor, Head of Research and Development Department, LLC RPE "Life Force". Russia.

Keywords: products based on humic acids; cucumber; irrigation; dark chestnut soils.

Studies to determine the effect of humic products produced by LIFE FORCE LLC, RPE were carried out on irrigated dark chestnut soils of the Saratov Trans- volga region. The yield and fruit quality of cucumber hybrid "Meringo" were studied during the experiment. It was established that a single application of K-Humate-Na with micronutrients solution increased the yield of marketable fruit for approximately three years by $24 \%$ towards the control. When there was applied Reasil ${ }^{\circledR}$ micro Hydro Mix, the yield increase reached $36 \%$. The above mentioned treatments combined with double applications of Reasil ${ }^{\circledR}$ Forte Carb$\mathrm{N}$-Humic or Reasi ${ }^{\circledR}$ Forte Carb-Ca/Mg/B-Amino, allowed to increase fruit yield by $51-52 \%$. The treatment of cucumber with solution of humic acids products promoted an increase in the content of compounds of nitrogen, potassium and content of sugars and vitamin $C$ in fruit. . There was stated that the content of nitrates was five times lower the permissible limits when applied to all groups and during the whole period of experiment. 